\title{
Notch1 is a potential therapeutic target for the treatment of human hepatitis B virus X protein-associated hepatocellular carcinoma
}

\author{
QIAN SUN* ${ }^{*}$ RONGHUA WANG* ${ }^{*}$ YAN WANG, JING LUO, PENG WANG and BIN CHENG \\ Department of Gastroenterology and Hepatology, Tongji Hospital, Tongji Medical College, \\ Huazhong University of Science and Technology, Wuhan 430030, P.R. China
}

Received October 29, 2013; Accepted November 27, 2013

DOI: $10.3892 /$ or.2013.2917

\begin{abstract}
Hepatocellular carcinoma (HCC) is a highly lethal cancer with increasing worldwide incidence, and there are few therapeutics options available for patients with HCC. Thus, novel therapeutic targets for this disease are desperately needed. Chronic infection with hepatitis B virus (HBV) is the major risk factor for the development of $\mathrm{HCC}$, while hepatitis $\mathrm{B}$ virus $\mathrm{X}$ protein $(\mathrm{HBx})$ is essential for $\mathrm{HBV}$-associated $\mathrm{HCC}$. Based on our previous studies showing that $\mathrm{HBx}$ promoted hepatocarcinogenesis of the human non-tumor hepatic cell line L02 and activated Notch1 signaling, Notch1 short hairpin RNA (shRNA) was utilized to inhibit Notch1 mRNA in the present study. We observed that Notch1 shRNA inhibited cell proliferation together with decreased activity of the Notch1 pathway in vitro, and also markedly suppressed tumor formation of L02/HBx cells in a BALB/c nude mouse model in vivo. Furthermore, the blockade of Notch1 was capable of arresting the cell cycle in the G0/G1 phase through the downregulation of CyclinD1, CDK4, E2F1 and the upregulation of $\mathrm{p} 21$ and $\mathrm{Rb}$, while all of these factors were involved in the CyclinD1/CDK4 pathway. Inhibition of Notch1 by shRNA markedly promoted
\end{abstract}

Correspondence to: Professor Bin Cheng, Department of Gastroenterology and Hepatology, Tongji Hospital, Tongji Medical College, Huazhong University of Science and Technology, Jiefang Street 1095, Wuhan 430030, P.R. China

E-mail: b.cheng@tjh.tjmu.edu.cn

*Contributed equally

Abbreviations: $\mathrm{HCC}$, hepatocellular carcinoma; HBV, hepatitis B virus; HBx, hepatitis B virus X protein; Notch-IC or NICD, Notch intracellular domain; CSL, mammalian CBF1, Drosophila $\mathrm{Su}(\mathrm{H})$, C. elegans LAG-1; Hes, hairy and enhancer of split family; qRT-PCR, quantitative real-time RT-PCR; CDK, cyclin-dependent kinases; EF, transcription factor; p21, CDK-interacting protein/kinase inhibitor protein; $\mathrm{Rb}$, retinoblastoma protein; $\mathrm{pRb}$, hyperphosphorylation of retinoblastoma protein

Key words: hepatocellular carcinoma, hepatitis B virus $\mathrm{X}$ protein, Notch1, Notch signaling, RNA interference the apoptosis of L02/HBx cells via the caspase-9-caspase-3 pathway. These data suggest that inhibition of Notch1 impairs the growth of human HBx-transformed L02 cells, and Notch1 may be a putative therapeutic target for human $\mathrm{HBx}$-associated HCC.

\section{Introduction}

Hepatocellular carcinoma (HCC) is the fifth most common cancer and the third leading cause of cancer-related mortality worldwide (1). Hepatitis B virus (HBV) infection is one of the major causes of HCC (2). The hepatitis B virus (HBV) X gene, which encodes the hepatitis $B$ virus $X$ protein $(\mathrm{HBx})$, is essential for the early steps of infection during the viral life cycle, viral genome replication, $\mathrm{HBV}$-associated diseases and development of HCC (3). HCC is a disease with an extremely poor prognosis, and there are limited therapeutic regimens available for the effective treatment of liver cancer. Thus, it is crucial to discover novel therapeutic targets for this disease.

The Notch signaling pathway is evolutionarily conserved and plays crucial roles in the development and maintenance of embryonic and adult tissues $(4,5)$. In mammals, there are four Notch receptors (Notch14), three Delta-like ligands (D111, Dll3 and Dll4), and two ligands of the Jagged family (Jag1 and Jag2). Cell-to-cell contact is a prerequisite for the activation of Notch signaling (6). When membrane-bound receptors interact with cognate ligands on an adjacent cell, two consecutive proteolytic cleavages of the receptor are initiated that enable the intracellular portion of Notch (NICD) to enter the nucleus. In the nucleus, the NICD interacts with DNA-bound protein factors (CSL/CBF1/RBPj $\gamma$ ) and recruits MAML proteins to modulate the expression of many genes (7). One of these genes is the Notch target Hes1, whose increased expression is part of the mechanism by which Notch signaling influences cellular physiology. The functions of the Notch pathway are highly cell-type dependent in different embryonic and adult tissues, as well as in cancers (8).

The first evidence for the involvement of Notch signaling in cancer came from T lymphoblastic leukemia. In 1991, Ellisen et al (9) discovered that the chromosomal translocation $[t(7 ; 9)]$ leads to constitutive activation of Notch1 in human $\mathrm{T}$ lymphoblastic leukemia. Afterwards, the deregulation of Notch 
pathway in solid cancers was discovered. Depending on the type of tumor, Notch signaling can serve either as a tumor promoter or a suppressor. Growing evidence has revealed the oncogenic function of Notch1 in lung adenomas, glioma, colon cancers, breast cancer, prostate cancer, renal cancer and melanoma (10-16). However, the same signaling may have a growth suppressive effect in anaplastic thyroid carcinoma (17) and endometrial cancer (18). Conflicting results have been reported concerning the role of Notch1 in liver cancer. Qi et al (19) in 2003 demonstrated that the overexpression of Notch1 could act on different cell cycle regulators, and inhibit the proliferation of hepatocellular carcinoma (HCC) cells by inducing a G0/G1 phase cell cycle arrest. Notch1 was shown to induce apoptosis of HCC cells by altering the balance between p53 and Bcl-2. In 2011, Viatour et al (20) established a mouse model of HCC made by genetic inactivation of the retinoblastoma (RB) pathway, and activation of Notch signaling was found to reduce HCC cell proliferation and tumor growth. In contrast with these findings, Giovannini et al (21) reported aberrant nuclear expression of Notch1 and Notch3 in neoplastic hepatocytes as compared to the surrounding cirrhotic tissue. Therefore, the role of Notch1 signaling in HCC merits further investigation.

We previously reported that $\mathrm{HBx}$-induced malignant transformation of human hepatic cells was associated with upregulation of Notch1 signaling (22). In the present study, we aimed to determine whether Notch1 functions as a potential therapeutic target in human HBx-associated HCC. To address this issue, we investigated the effects of Notch1 signaling in L02/HBx cells by knockdown of the Notch1 gene using shRNA.

\section{Materials and methods}

Cell culture. The L02/HBx cell line, which was derived from L02 cells by transfection with the HBx expression plasmid, was successfully established as previously described (23). The cells were cultured in DMEM (Gibco, Carlsbad, CA, USA) supplemented with $10 \%$ fetal bovine serum (FBS; Gibco, Grand Island, NY, USA) and $250 \mu \mathrm{g} / \mathrm{ml} \mathrm{G} 418$ (Invitrogen, Carlsbad, CA, USA) and maintained in a humidified incubator at $37^{\circ} \mathrm{C}$ in a $5 \% \mathrm{CO}_{2}$ atmosphere.

Plasmid constructs and transfections. Two shRNA sequences were designed against the Notch1 sequence (NM_017617): 1, 5'-GGTGTCTTCCAGATCCTGA-3'; 2, 5'-TGGCGGGAA GTGTGAAGCG-3'. After synthesis of the oligoduplexes, the pH1-MCS-CMV-GFP-Hygro plasmid vector was digested with BamHI and HindIII restriction endonucleases. Next, the Notch1-specific shRNAs were cloned into the pH1-MCSCMV-GFP-Hygro vector. The successful plasmid construction was verified by DNA sequencing. The pH1-MCS-CMV-GFPHygro-Notch1 shRNA1, 2 and the pH1-MCS-CMV-GFPHygro negative control vector were transfected into $80 \%$ confluent L02/HBx cells, respectively, with Lipofectamine 2000 reagent (Invitrogen) according to the manufacturer's recommended conditions. After $48 \mathrm{~h}$, the transfected cells were selected for 3 weeks with $100 \mu \mathrm{g} / \mathrm{ml}$ hygromycin B (Sigma, St. Louis, MO, USA) to obtain stable Notch1-knockdown cell lines. Individual colonies were selected and then the stable cells were expanded in DMEM with $50 \mu \mathrm{g} / \mathrm{ml}$ hygromycin B.
Cell proliferation and viability assay. L02/HBx, negative control and L02/HBx-Notch1shRNA cells were seeded in a 96-well plate with $10^{4}$ cells per well, and the Cell Counting Kit-8 (Dojindo Laboratories, Kumamoto, Japan) was used to assess cell proliferation at the indicated times $(24,48,72$, $96 \mathrm{~h}$ ). The absorbance value at $450 \mathrm{~nm}$ was measured using a spectrophotometer after incubation with the WST-8 reagent (10 $\mu \mathrm{l}$ ) for $2 \mathrm{~h}$; $630 \mathrm{~nm}$ was the reference wavelength. All experiments were repeated eight times.

Analysis of cell cycle distribution and apoptosis by flow cytometry. L02/HBx, negative control and L02/HBx-Notch1shRNA cells were harvested and immediately fixed in ice-cold $70 \%$ ethanol for $1 \mathrm{~h}$, and were then treated with $1 \mathrm{mg} / \mathrm{ml}$ RNase A (Invitrogen) for $30 \mathrm{~min}$ at $37^{\circ} \mathrm{C}$. Cells were then stained with $50 \mu \mathrm{g} / \mathrm{ml}$ PI solution (Sigma) for $30 \mathrm{~min}$ and analyzed by flow cytometry. Analysis of apoptosis was performed using the PE Annexin V Apoptosis Detection kit I (BD Biosciences, USA) according to the manufacturer's instructions. The percentage of cells that stained positive for PE Annexin V was compared among the different treatment groups.

Quantitative real-time PCR ( $q R T-P C R)$. Total RNA was isolated from cultured cells using TRIzol reagent (Invitrogen) and cDNA was synthesized from 100 ng RNA using the PrimeScript RT reagent kit (Takara, Japan). Real-time quantitative PCR using SYBR Premix (Takara) was performed as described previously (24). Amplifications were performed in a Step One Real-Time PCR system (Applied Biosystems, USA) following the manufacturer's instructions. The expression of RNA was determined from the threshold cycle $(\mathrm{Ct})$, and the relative expression levels were calculated by the $2^{-\Delta \Delta \mathrm{Ct}}$ method. All samples were assayed in triplicate. The primer sequences used to amplify the specific target genes are listed in Table I.

Western blot analysis. The total protein was extracted from L02/HBx, negative control and L02/HBx-Notch1shRNA cell lines using RIPA buffer (Sigma). The protein concentrations were determined with the BCA protein assay kit (Pierce, Rockford, IL, USA). Protein (40 $\mu \mathrm{g}$ ) from each sample was examined by SDS-12\% PAGE and then electrotransferred to nitrocellulose membranes using a semi-dry transfer apparatus (Bio-Rad). Nitrocellulose membranes were subsequently blocked with 5\% BSA in TBST for $2 \mathrm{~h}$ at room temperature, and incubated with each primary antibody overnight. Rabbit anti-Notch1, -CyclinD1, -CDK4, -E2F1, -p21, -Rb, -CyclinE1, -caspase-3, -caspase-9 were purchased from Proteintech Group (Chicago, IL, USA), and rabbit anti-Hes1, -caspase-8, -actin were obtained from Santa Cruz Biotechnology (Santa Cruz, CA, USA). The membranes were washed and incubated with horseradish peroxidase-labeled secondary antibody (1:4,000; Santa Cruz Biotechnology), and visualization was performed by an enhanced chemiluminescence kit (Pierce) and exposure to X-ray film (Kodak, Rochester, NY, USA). Immunoblotting with the anti-actin antibody was used as an internal control to confirm equivalent protein loading. Each experiment was repeated three times.

Analysis of colony formation. For clonogenicity analysis, 1000 viable cells (L02/HBx, negative control, 
Table I. Primer sequences for the quantitative RT-PCR analysis.

\begin{tabular}{|c|c|c|c|c|}
\hline Gene & & Sequences & PCR product (bp) & GenBank accession no. \\
\hline Notch1 & $\begin{array}{l}\text { Sense } \\
\text { Antisense }\end{array}$ & $\begin{array}{l}\text { 5'-CCGCAGTTGTGCTCCTGAA-3' } \\
\text { 5'-ACCTTGGCGGTCTCGTAGCT-3' }\end{array}$ & 109 & NM_017617 \\
\hline Hes1 & $\begin{array}{l}\text { Sense } \\
\text { Antisense }\end{array}$ & $\begin{array}{l}\text { 5'-GCTAAGGTGTTTGGAGGCT-3' } \\
\text { 5'-CCGCTGTTGCTGGTGTA-3' }\end{array}$ & 122 & NM_005524 \\
\hline CyclinD1 & $\begin{array}{l}\text { Sense } \\
\text { Antisense }\end{array}$ & $\begin{array}{l}\text { 5'-GGCTGAAGTCACCTCTTGGTTACAG-3' } \\
\text { 5'-TAGCGTATCGTAGGAGTGGGACAG-3' }\end{array}$ & 177 & NM_053056 \\
\hline CDK4 & $\begin{array}{l}\text { Sense } \\
\text { Antisense }\end{array}$ & $\begin{array}{l}\text { 5'-TGGTGTCGGTGCCTATGG-3' } \\
\text { 5'-GAACTGTGCTGATGGGAAGG-3' }\end{array}$ & 128 & NM_000075 \\
\hline $\mathrm{E} 2 \mathrm{~F} 1$ & $\begin{array}{l}\text { Sense } \\
\text { Antisense }\end{array}$ & $\begin{array}{l}\text { 5'-CCAGGAAAAGGTGTGAAATC-3 } \\
\text { 5'-AAGCGCTTGGTGGTCAGATT-3' }\end{array}$ & 74 & NM_005225' \\
\hline $\mathrm{p} 21$ & $\begin{array}{l}\text { Sense } \\
\text { Antisense }\end{array}$ & $\begin{array}{l}\text { 5'-TGATTAGCAGCGGAACAAGGAG-3' } \\
\text { 5'-GGAGAAACGGGAACCAGGACAC-3' }\end{array}$ & 254 & NM_000389 \\
\hline $\mathrm{Rb}$ & $\begin{array}{l}\text { Sense } \\
\text { Antisense }\end{array}$ & $\begin{array}{l}\text { 5'-TCAAGGGTCATTATGGGTTAGGC-3' } \\
\text { 5'-CTTTAGGTGTAGGGGAGGGGAG-3' }\end{array}$ & 115 & NM_000321 \\
\hline CyclinE1 & $\begin{array}{l}\text { Sense } \\
\text { Antisense }\end{array}$ & $\begin{array}{l}\text { 5'-CCTGGATGTTGACTGCCTTGA-3' } \\
\text { 5'-CTATGTCGCACCACTGATACCCT-3' }\end{array}$ & 116 & NM_001238 \\
\hline Caspase-3 & $\begin{array}{l}\text { Sense } \\
\text { Antisense }\end{array}$ & $\begin{array}{l}\text { 5'-GGTTCATCCAGTCGCTTTG-3' } \\
\text { 5'-ATTCTGTTGCCACCTTTCG-3' }\end{array}$ & 99 & NM_032991 \\
\hline Caspase-9 & $\begin{array}{l}\text { Sense } \\
\text { Antisense }\end{array}$ & $\begin{array}{l}\text { 5'-GCGAACTAACAGGCAAGCA-3' } \\
\text { 5'-CATCACCAAATCCTCCAGAAC-3' }\end{array}$ & 149 & NM_032996 \\
\hline Caspase- 8 & $\begin{array}{l}\text { Sense } \\
\text { Antisense }\end{array}$ & $\begin{array}{l}\text { 5'-AGAGTCTGTGCCCAAATCAAC-3' } \\
\text { 5'-GCTGCTTCTCTCTTTGCTGAA-3' }\end{array}$ & 78 & NM_033358 \\
\hline Actin & $\begin{array}{l}\text { Sense } \\
\text { Antisense }\end{array}$ & $\begin{array}{l}\text { 5'-GTTGCGTTACACCCTTTCTTG-3' } \\
\text { 5'-GACTGCTGTCACCTTCACCGT-3' }\end{array}$ & 157 & NM_001101 \\
\hline
\end{tabular}

L02/HBx-Notch1shRNA) were placed in 6-well plates and maintained in complete medium for 2 weeks. Colonies were fixed with methanol and stained with methylene blue.

Xenograft tumor model. Twelve male BALB/c-nu/nu mice (body weight, $\sim 19 \mathrm{~g}$; age, 4 weeks) were purchased from the Animal Centre of Tongji Medical College, Huazhong University of Science and Technology (Wuhan, China). All animal experiments were approved by the Institutional Animal Care and Use Committee of the Huazhong University of Science and Technology. The mice were randomized into two groups ( $\mathrm{n}=6$ in each group), and housed at the Animal Institute of Tongji Medical College in laminar flow cabinets. Cells $\left(2 \times 10^{6}\right)$ (negative control, L02/HBx-Notch1shRNA) in $0.2 \mathrm{ml}$ were subcutaneously injected into the posterior neck of each nude mouse. The length (L) and width (W) of the tumors were measured externally with a vernier caliper every 4 days. Tumor volume was calculated with the formula: $\mathrm{V}=\left(\mathrm{LxW}^{2}\right) / 2$. After 25 days, the tumor-bearing mice and controls were sacrificed, and the tumors were excised and measured.

Histology and immunohistochemistry. Tumor samples were verified as being $\mathrm{HCC}$ by hematoxylin and eosin (H\&E) staining and were subjected to immunohistochemical examination to determine the presence of HBx. For histologic analysis, tissues were fixed in $4 \%$ paraformaldehyde at $4^{\circ} \mathrm{C}$, embedded in paraffin, cut into $5-\mu \mathrm{m}$ sections, and transferred to siliconcoated slides. Tissue sections were then stained with H\&E. For immunohistochemical analysis, staining for Notch1 was carried out using rabbit polyclonal antibodies against Notch1 (Proteintech Group) at a dilution of 1:50. Visualization was performed using 3,3'-diaminobenzidine tetrahydrochloride (DAB; Vector Laboratories, Burlingame, CA, USA), followed by counterstaining with Mayer's hematoxylin (Merck, Darmstadt, Germany).

Statistical analysis. Each experiment was repeated at least three times. The data are presented as means \pm SEM. SPSS version 17.0 software (SPSS for Windows, Inc., Chicago, IL, USA) was used for all statistical analyses. Statistical analysis of data was performed using standard one-way ANOVA or one-way ANOVA for repeated measures, followed by Bonferroni post-hoc test. A 2-tailed Student's paired t-test was used to compare the difference in values between two groups. A P-value $<0.05$ was considered to indicate a statistically significant result.

\section{Results}

Blockage of Notchl signaling in L02/HBx cells by Notch1shRNA. DNA sequencing of the recombinant plasmid showed successful construction of the pH1-MCS-CMV- 

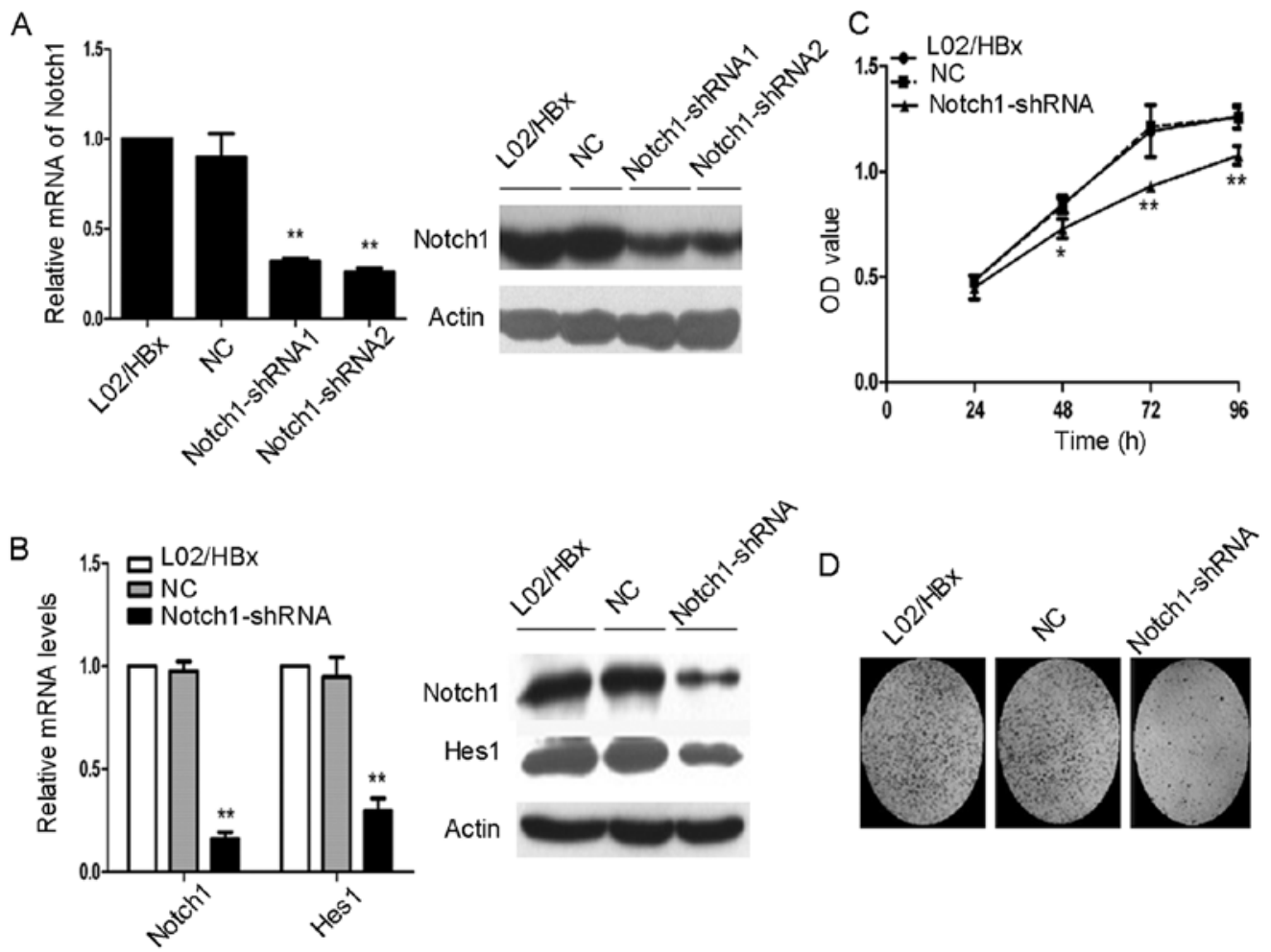

Figure 1. Notch1-shRNA suppresses L02/HBx cell proliferation in vitro. (A) Identification of the effective shRNA targeting the Notch1 gene. The relative mRNA and protein levels of Notch1 were assessed by qRT-PCR and western blotting in L02/HBx cells $48 \mathrm{~h}$ after transient transfection with Notch1-shRNA1, Notch1-shRNA2 or negative control-shRNA (NC), respectively. (B) The components of the Notch1 signaling pathway were downregulated in the L02/ HBx-Notch1 shRNA2 cells. The mRNA and protein expression levels of Notch1 and Hes1 were assessed by qRT-PCR and western blotting, respectively. Actin was used as a loading control for both quantitative RT-PCR and western blotting. (C) CCK-8 assay and (D) colony formation assay of L02/HBx cells stably transfected with control or Notch1 shRNA2. Data are shown as the mean \pm SEM from at least three independent experiments. Statistically significant differences are indicated as ${ }^{*} \mathrm{P}<0.05,{ }^{* *} \mathrm{P}<0.01$ vs. L02/HBx cells.

GFP-Hygro-Notch1 shRNA1, 2 (Notch1-shRNA1, 2) and the pH1-MCS-CMV-GFP-Hygro negative control vector (NC). To assess the RNAi efficiency, the expression of Notch1 in L02/HBx cells was determined by qRT-PCR and western blotting $48 \mathrm{~h}$ after transient transfection with the shRNAs. Compared to the non-transfected cells, transfection of Notch1-shRNA1 or 2 into L02/HBx cells resulted in the downregulation of Notch1 mRNA expression up to 68 or $74 \%$, respectively; the expression of Notch1 protein was also markedly reduced (Fig. 1A, P<0.01), while no significant changes in the NC-transfected group were noted. Thus, Notch1-shRNA2 was chosen for further study. After stable transfection with Notch1-shRNA2, both mRNA expression and protein expression of Notch1 and Hes1 was markedly suppressed when compared to the non-transfected cells (Fig. 1B; $\mathrm{P}<0.01$ ). Since Hes1 is a target gene of Notch signaling, these results indicated that Notch1 signaling in L02/HBx cells was partially blocked by Notch1-shRNA2.

Inhibition of Notch1 impairs the growth of L02/HBx cells. Based on the hypothesis that Notch1 signaling is involved in $\mathrm{HBx}-$ enhanced cell proliferation, we performed CCK-8 and colony formation assays in the $\mathrm{L} 02 / \mathrm{HBx}$ cells. The data clearly indicated that the proliferation of L02/HBx cells was significantly reduced by Notch1-shRNA in vitro (Fig. 1C and $\mathrm{D} ; \mathrm{P}<0.05, \mathrm{P}<0.01)$. Coincidentally, the tumorigenicity was markedly suppressed in nude mice injected with L02/HBx cells pre-treated with Notch1-shRNA in vivo (Fig. 2A and B; $\mathrm{P}<0.05, \mathrm{P}<0.01)$. Pathological examination of the primary tumors revealed malignant phenotypes in both groups by H\&E staining (Fig. 2C). Meanwhile, the effective inhibition of Notch1 in vivo was confirmed by immunoreactivity analysis in the tumor tissues from the mice (Fig. 2D).

Inhibition of Notchl induces cell cycle arrest via the CyclinD1/CDK4 pathway in L02/HBx cells. Compared to the non-transfected cells, the proportion of cells in the G0/ G1 phase was markedly increased, and cells in the $S$ phase were decreased significantly by knockdown of Notch1 signaling with Notch1-shRNA (Fig. 3A; P<0.01). Moreover, the expression levels of CyclinD1, CyclinE1, CDK4, E2F1, p21 and Rb were measured by qRT-PCR and western blotting, and we demonstrated that, following the knockdown of Notch1 expression in L02/HBx cells, the expression levels of CyclinD1, CDK4 and E2F1 were significantly decreased, while the expression of $\mathrm{p} 21$ and $\mathrm{Rb}$ was significantly increased; however, the expression of CyclinE1 remained unaltered (Fig. 3B; P<0.01).

Inhibition of Notchl induces apoptosis via the caspase-9caspase-3 pathway in LO2/HBx cells. We found that apoptosis was significantly increased in the shRNA transfected cells when compared to that in the non-transfected cells (Fig. 4A; $\mathrm{P}<0.05)$. qRT-PCR and western blot analysis showed that, 


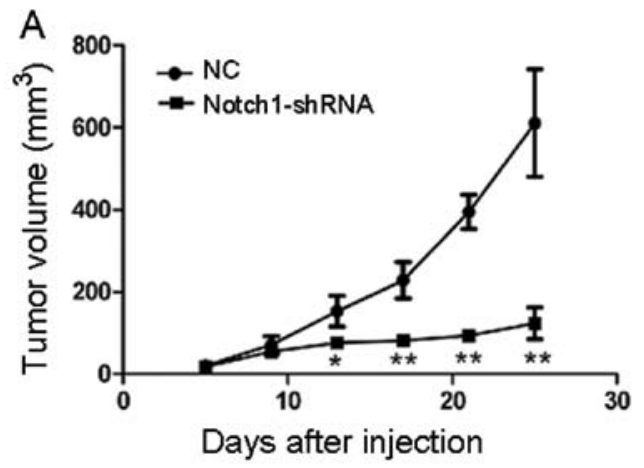

B NC
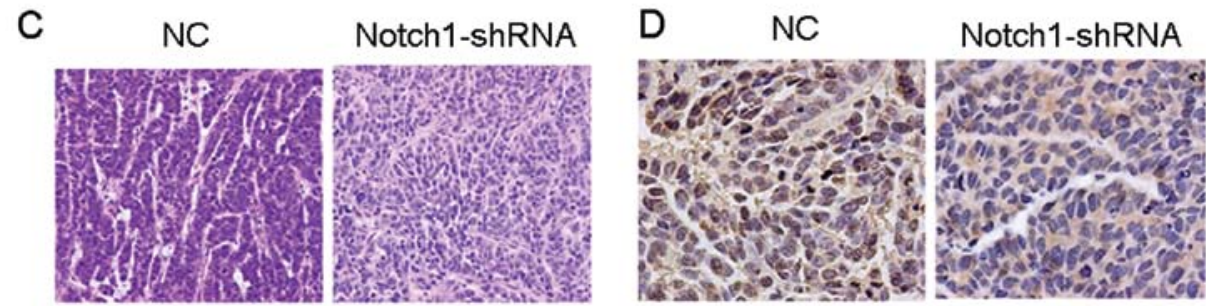

Figure 2. Notch1-shRNAs suppresses L02/HBx cell proliferation in vivo. (A) The growth curve of the tumors derived from L02/HBx cells pretreated with Notch1-shRNA or control-shRNA in nude mice. Data represent means \pm SEM of six samples. ${ }^{*} \mathrm{P}<0.05,{ }^{* *} \mathrm{P}<0.01$. (B) Images of representative mice and dissected tumors from nude mice. (C) Tumor tissues from nude mice inoculated with NC or Notch1-shRNA cells were stained with hematoxylin and eosin (H\&E). Original magnification, x200. (D) Immunohistochemistry of Notch1 expression in tumor tissues from nude mice. Original magnification, x400.
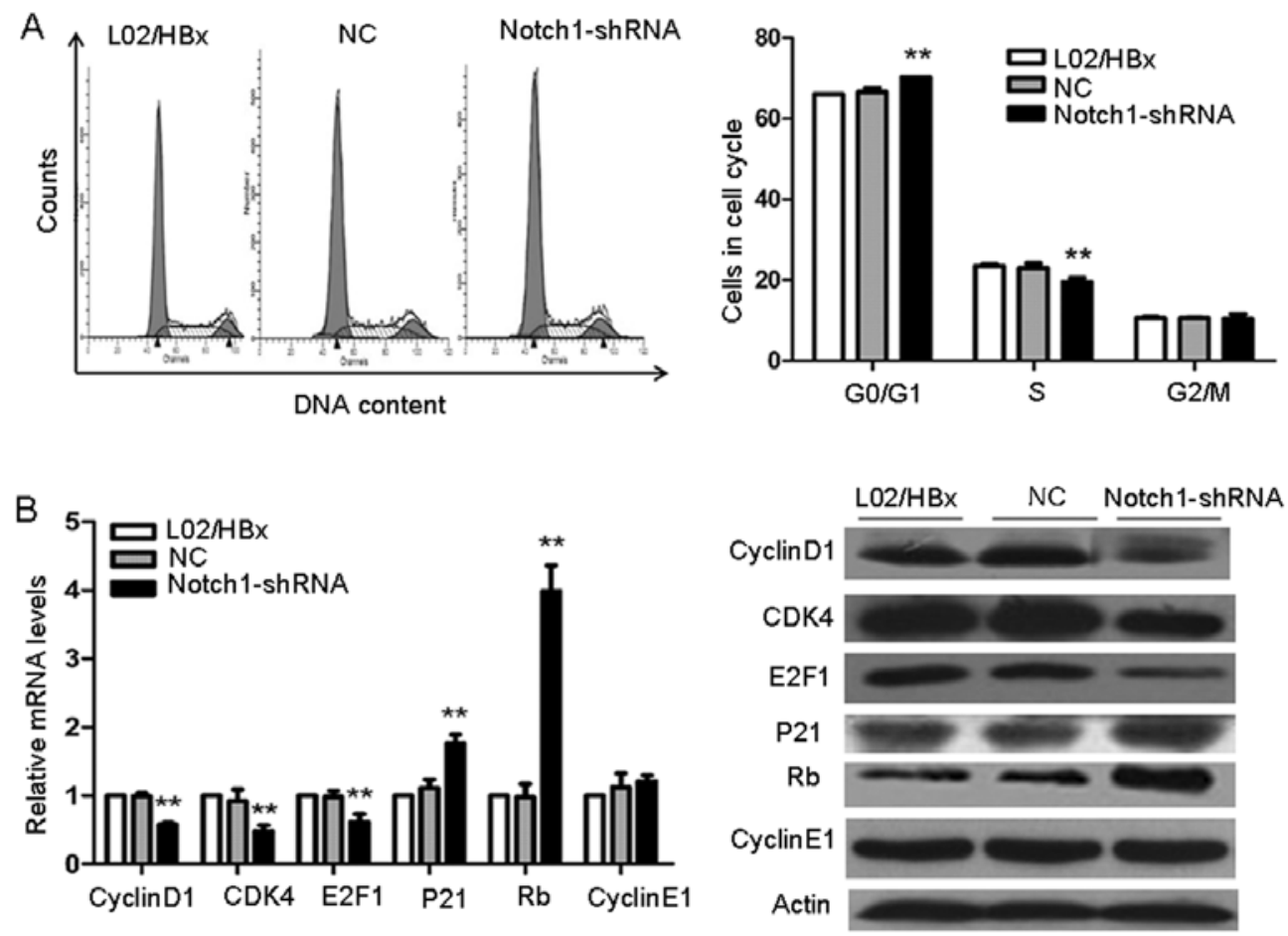

Figure 3. Notch1-shRNA induces cell cycle arrest via the CyclinD1/CDK4 pathway in L02/HBx cells. (A) Notch1-shRNA induced cell cycle arrest in L02/ HBx cells. Cell cycle distribution was examined by flow cytometry after staining with PI. Results are visualized as a representative experiment or means \pm SEM of three experiments. (B) Notch1-shRNA downregulates the CyclinD1/CDK4 pathway in L02/HBx cells. The expression levels of cell cycle regulatory genes CyclinD1, CDK4, E2F1, Rb, p21 and CyclinE1 were analyzed by qRT-PCR and western blotting. Data represent the mean \pm SEM from three independent experiments. Statistically significant differences are indicated as ${ }^{*} \mathrm{P}<0.05,{ }^{* *} \mathrm{P}<0.01$ vs. L02/HBx cells.

compared to the control and mock groups, the expression of caspase- 3 and -9 was increased at both the mRNA and protein levels, while no significant changes in caspase- 8 expression were noted (Fig. 4B; $\mathrm{P}<0.01$ ).

\section{Discussion}

Hepatocellular carcinoma (HCC) is a highly lethal cancer with increasing worldwide incidence, which is mainly attributed 
A

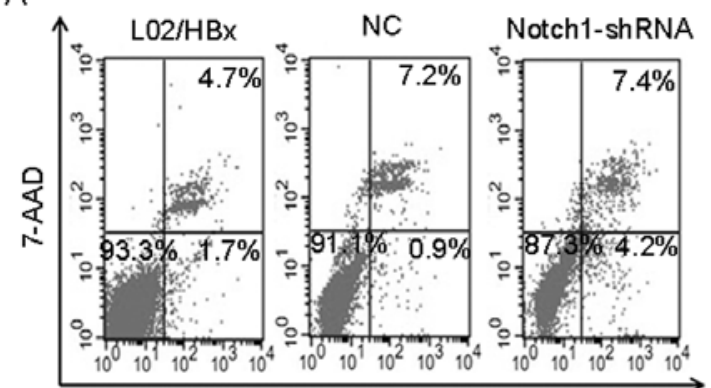

PE Annexin V

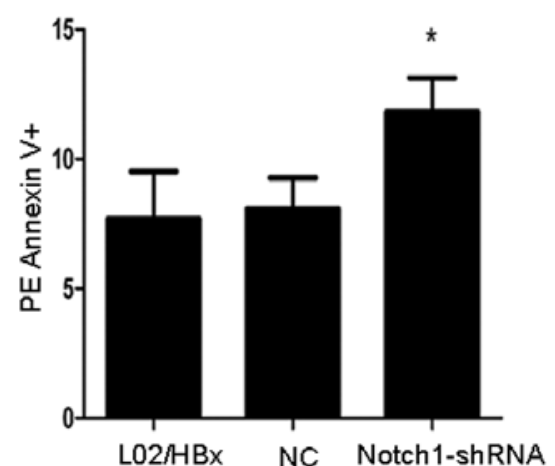

L02/HBx NC Notch1-shRNA
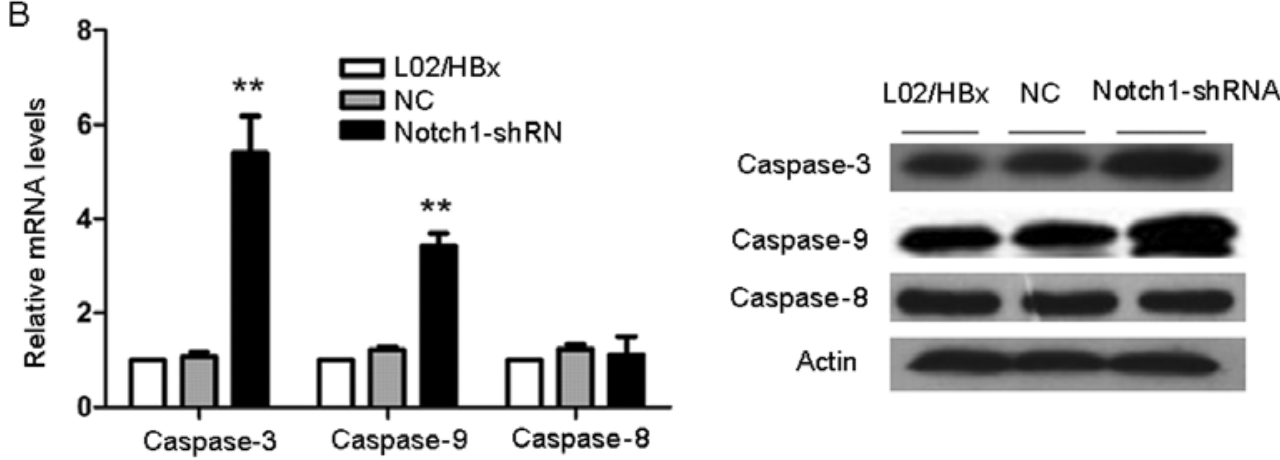

Figure 4. Notch1-shRNA increases cell apoptosis via the caspase-9-caspase-3 pathway in L02/HBx cells. (A) Notch1-shRNA increased cell apoptosis in L02/ $\mathrm{HBx}$ cells. Analysis of apoptosis was performed using PE Annexin V and 7-AAD staining by FACS analysis. Results are visualized as a representative experiment or means \pm SEM of three experiments. (B) Notch1-shRNA upregulated the caspase-9-caspase-3 pathway in L02/HBx cells. The expression of caspase-9, -8 and -3 was analyzed by qRT-PCR and western blotting. Data are shown as the mean \pm SEM of three independent experiments. Statistically significant differences are indicated as ${ }^{*} \mathrm{P}<0.05,{ }^{* *} \mathrm{P}<0.01$ vs. $\mathrm{L} 02 / \mathrm{HBx}$ cells.

to chronic hepatitis B virus (HBV) infection. Our previous study demonstrated that HBx can act as an oncogenic factor to promote hepatocarcinogenesis and progression by binding to NICD, which was related to Notch1 signaling (22,24-25). In the present study, we employed plasmid-based shRNA to knock down the Notch1 signaling pathway, and we found that cell proliferation and tumor formation of $\mathrm{L} 02 / \mathrm{HBx}$ cells were significantly impaired. Several studies have provided strong evidence in favor of the pro-oncogenic activity of Notch1 in HCC. It was reported that Notch1 activation promoted human HCC cell growth, proliferation (26) and invasiveness (27), and downregulation of Notch1 led to reduced invasion and migration of HCC cells (28). Thus, our findings are consistent with those studies.

Cell cycle arrest and increased apoptosis are crucial for controlling the malignancy of transformed cells. In this study, we observed that knockdown of Notch1 led to G0/G1 phase cell cycle arrest and increased apoptosis in HBx-transformed L02 cells. Growing evidence has demonstrated that downregulation of cell cycle regulators is regarded as one of the important causes of the early steps of hepatocarcinogenesis (29). It has been reported that G0/G1 phase arrest and the overexpression of CyclinD1 and CyclinE play pivotal roles in $\mathrm{HCC}(30,31)$. To our knowledge, Cyclin D1 and Cyclin E respectively interact with CDK4 and CDK2, and then produce Cyclin D1/CDK4 and Cyclin E/CDK2 complexes in the early G1 phase. These Cyclin/CDK complexes are required for hyperphosphorylation of retinoblastoma protein $(\mathrm{pRb})$ and dissociation of transcription factor $\mathrm{E} 2 \mathrm{~F}$ from $\mathrm{Rb}$, leading to the transcription of genes implicated in $\mathrm{S}$ phase progression. Conversely, G1 phase-related Cyclin/CDK complexes are negatively regulated by $\mathrm{p} 21$. In this study, the key cycle regulators of CyclinD1 and CyclinE1 pathway were assessed following Notch1 inhibition.

Our data showed that Notch1 suppression by shRNA led to the decreased expression of CyclinD1, CDK4 and E2F1, and increased expression of p21 and Rb; however, CyclinE1 remained unchanged. Apoptosis can be initiated by extrinsic (originating outside a cell) or intrinsic (originating inside a cell) signaling pathways (32). Caspase- 8 is an initiator caspase which is activated in the extrinsic pathway of apoptosis and cleaves downstream caspases to eventually activate the executioner caspase, caspase-3 (33). Caspase-9 which activates caspase-3, participates in the intrinsic pathway. In the present study, Notch1 suppression by shRNA resulted in the increased expression of caspase-3 and -9; however, caspase- 8 remained unchanged. Research has revealed that aberrant expression of these proteins facilitates tumor progression in the early stages of hepatocarcinogenesis (34).

In conclusion, the blockade of Notch1 signaling was capable of suppressing the growth of L02/HBx cells both in vitro and in vivo which was associated with the arrest of the cell cycle in the G0/G1 phase via the CyclinD1/CDK4 pathway and the promotion of apoptosis via the caspase-9-caspase-3 pathway. Thus, Notch1 may serve as a potential therapeutic target for HBx-associated HCC.

\section{Acknowledgements}

This study was supported by the National Science Foundation of China, grant nos. 30971352 and 81172063. 


\section{References}

1. El-Serag HB and Rudolph KL: Hepatocellular carcinoma: epidemiology and molecular carcinogenesis. Gastroenterology 132 : 2557-2576, 2007

2. Engelke M, Mills K, Seitz S, et al: Characterization of a hepatitis $\mathrm{B}$ and hepatitis delta virus receptor binding site. Hepatology 43: 750-760, 2006

3. Ye L, Dong N, Wang Q, et al: Progressive changes in hepatoma cells stably transfected with hepatitis B virus $\mathrm{X}$ gene. Intervirology 51: 50-58, 2008.

4. Artavanis-Tsakonas S: The molecular biology of the Notch locus and the fine tuning of differentiation in Drosophila. Trends Genet 4: 95-100, 1988.

5. Leong KG and Karsan A: Recent insights into the role of Notch signaling in tumorigenesis. Blood 107: 2223-2233, 2006.

6. Gridley T: Notch signaling and inherited disease syndromes. Hum Mol Genet 12 (Spec No. 1): R9-R13, 2003.

7. Kopan R and Ilagan MX: The canonical Notch signaling pathway: unfolding the activation mechanism. Cell 137: 216-233, 2009.

8. Koch U and Radtke F: Notch signaling in solid tumors. Curr Top Dev Biol 92: 411-455, 2010.

9. Ellisen LW, Bird J, West DC, et al: TAN-1, the human homolog of the Drosophila notch gene, is broken by chromosomal translocations in T lymphoblastic neoplasms. Cell 66: 649-661, 1991.

10. Allen TD, Rodriguez EM, Jones KD, et al: Activated Notch1 induces lung adenomas in mice and cooperates with Myc in the generation of lung adenocarcinoma. Cancer Res 71: 6010-6018, 2011.

11. Li J, Cui Y, Gao G, et al: Notch1 is an independent prognostic factor for patients with glioma. J Surg Oncol 103: 813-817, 2011.

12. Zhang Y, Li B, Ji ZZ, et al: Notch1 regulates the growth of human colon cancers. Cancer 116: 5207-5218, 2010.

13. Zardawi SJ, Zardawi I, McNeil CM, et al: High Notch1 protein expression is an early event in breast cancer development and is associated with the HER-2 molecular subtype. Histopathology 56: 286-296, 2010

14. Bin Hafeez B, Adhami VM, Asim M, et al: Targeted knockdown of Notch1 inhibits invasion of human prostate cancer cells concomitant with inhibition of matrix metalloproteinase- 9 and urokinase plasminogen activator. Clin Cancer Res 15: 452-459, 2009.

15. Sjolund J, Johansson M, Manna S, et al: Suppression of renal cell carcinoma growth by inhibition of Notch signaling in vitro and in vivo. J Clin Invest 118: 217-228, 2008.

16. Balint K, Xiao M, Pinnix CC, et al: Activation of Notch1 signaling is required for beta-catenin-mediated human primary melanoma progression. J Clin Invest 115: 3166-3176, 2005.

17. Yu XM, Phan T, Patel PN, et al: Chrysin activates Notch1 signaling and suppresses tumor growth of anaplastic thyroid carcinoma in vitro and in vivo. Cancer 119: 774-781, 2013.

18. Jonusiene V, Sasnauskiene A, Lachej N, et al: Down-regulated expression of Notch signaling molecules in human endometrial cancer. Med Oncol 30: 438, 2013.
19. Qi R, An H, Yu Y, et al: Notch1 signaling inhibits growth of human hepatocellular carcinoma through induction of cell cycle arrest and apoptosis. Cancer Res 63: 8323-8329, 2003.

20. Viatour P, Ehmer U, Saddic LA, et al: Notch signaling inhibits hepatocellular carcinoma following inactivation of the RB pathway. J Exp Med 208: 1963-1976, 2011.

21. Giovannini C, Gramantieri L, Chieco P, et al: Selective ablation of Notch3 in HCC enhances doxorubicin's death promoting effect by a p53-dependent mechanism. J Hepatol 50: 969-979, 2009.

22. Wang F, Zhou H, Xia X, et al: Activated Notch signaling is required for hepatitis $\mathrm{B}$ virus $\mathrm{X}$ protein to promote proliferation and survival of human hepatic cells. Cancer Lett 298: 64-73, 2010.

23. Cheng B, Zheng Y, Guo X, et al: Hepatitis B viral X protein alters the biological features and expressions of DNA repair enzymes in LO2 cells. Liver Int 30: 319-326, 2010.

24. Luo J, Zhou H, Wang F, et al: The hepatitis B virus $\mathrm{X}$ protein downregulates $\mathrm{NF}-\kappa \mathrm{B}$ signaling pathways through decreasing the Notch signaling pathway in HBx-transformed L02 cells. Int J Oncol 42: 1636-1643, 2013.

25. Wang F, Zhou H, Yang Y, et al: Hepatitis B virus X protein promotes the growth of hepatocellular carcinoma by modulation of the Notch signaling pathway. Oncol Rep 27: 1170-1176, 2012.

26. Gao J, Dong Y, Zhang B, et al: Notch1 activation contributes to tumor cell growth and proliferation in human hepatocellular carcinoma HepG2 and SMMC7721 cells. Int J Oncol 41: 1773-1781, 2012

27. Lim SO, Park YM, Kim HS, et al: Notch1 differentially regulates oncogenesis by wildtype p53 overexpression and p 53 mutation in grade III hepatocellular carcinoma. Hepatology 53: 1352-1362, 2011.

28. Zhou L, Wang DS, Li QJ, et al: The down-regulation of Notch1 inhibits the invasion and migration of hepatocellular carcinoma cells by inactivating the cyclooxygenase-2/Snail/E-cadherin pathway in vitro. Dig Dis Sci 58: 1016-1025, 2013.

29. Greenbaum LE: Cell cycle regulation and hepatocarcinogenesis. Cancer Biol Ther 3: 1200-1207, 2004.

30. Lu JW, Lin YM, Chang JG, et al: Clinical implications of deregulated CDK4 and Cyclin D1 expression in patients with human hepatocellular carcinoma. Med Oncol 30: 379, 2013.

31. Pok S, Wen V, Shackel N, et al: Cyclin E facilitates dysplastic hepatocytes to bypass $\mathrm{G} / \mathrm{S}$ checkpoint in hepatocarcinogenesis. J Gastroenterol Hepatol 28: 1545-1554, 2013.

32. Tait SW and Green DR: Mitochondria and cell death: outer membrane permeabilization and beyond. Nat Rev Mol Cell Biol 11: 621-632, 2010.

33. Riedl SJ and Shi Y: Molecular mechanisms of caspase regulation during apoptosis. Nat Rev Mol Cell Biol 5: 897-907, 2004

34. Plati J, Bucur O and Khosravi-Far R: Apoptotic cell signaling in cancer progression and therapy. Integr Biol 3: 279-296, 2011. 